\title{
Limited sampling strategy to predict mycophenolic acid area under the curve in pediatric patients with nephrotic syndrome: a retrospective cohort study
}

\author{
Joanna Sobiak ${ }^{1}$ (D) $\cdot$ Matylda Resztak ${ }^{1} \cdot$ Tomasz Pawiński $^{2} \cdot$ Paweł Żero $^{2} \cdot$ Danuta Ostalska-Nowicka $^{3} \cdot$ Jacek Zachwieja $^{3}$. \\ Maria Chrzanowska ${ }^{1}$
}

Received: 7 January 2019 / Accepted: 27 May 2019 / Published online: 6 June 2019

(C) The Author(s) 2019

\begin{abstract}
Purpose Limited sampling strategy (LSS) is a precise and relatively convenient therapeutic drug monitoring method. We evaluated LSSs for mycophenolic acid (MPA) in children with nephrotic syndrome treated with mycophenolic mofetil (MMF) and validated the LSSs using two different approaches.

Methods We measured MPA plasma concentrations in 31 children using HPLC-UV method and received 37 MPA pharmacokinetic profiles $(0-12 \mathrm{~h})$. For six children, MPA profiles were estimated twice after two MMF doses. LSSs were developed using multilinear regression with STATISTICA and R software and validated using validation group and bootstrap method, respectively.

Results The best three time point equations included $\mathrm{C}_{1}, \mathrm{C}_{3}, \mathrm{C}_{6}$ (good guess $83 \%$, bias $-2.78 \%$; $95 \%$ confidence interval $(\mathrm{CI})-$ 9.85-0.46); $\mathrm{C}_{1}, \mathrm{C}_{2}, \mathrm{C}_{6}$ (good guess $72 \%$, bias $\left.0.72 \% ; 95 \% \mathrm{CI}-5.33-7.69\right) ;$ and $\mathrm{C}_{1}, \mathrm{C}_{2}, \mathrm{C}_{4}$ (good guess $72 \%$, bias $2.05 \%$; $95 \%$ $\mathrm{CI}-4.92-13.01$ ) for STATISTICA software. For R software, the best equations consisted of $\mathrm{C}_{1}, \mathrm{C}_{3}, \mathrm{C}_{6}$ (good guess $92 \%$, bias $2.69 \% ; 95 \% \mathrm{CI}-27.18-33.75$ ); $\mathrm{C}_{0}, \mathrm{C}_{1}, \mathrm{C}_{3}$ (good guess $84 \%$, bias $-2.11 \% ; 95 \% \mathrm{CI}-24.19-22.29$ ); and $\mathrm{C}_{0}, \mathrm{C}_{1}, \mathrm{C}_{2}$ (good guess $84 \%$, bias $-0.48 \%$; $95 \% \mathrm{CI}-30.77-54.07)$. During validation, better results were obtained for R evaluations, i.e., bootstrap method.

Conclusions The most useful equations included $\mathrm{C}_{0}, \mathrm{C}_{1}, \mathrm{C}_{3}$ and $\mathrm{C}_{0}, \mathrm{C}_{1}, \mathrm{C}_{2}$ time points; however, the most precise included $\mathrm{C}_{1}$, $\mathrm{C}_{3}, \mathrm{C}_{6}$ time points because of MPA enterohepatic recirculation. Better results were obtained for bootstrap validation due to greater number of patients. Validated LSS should be used only in the population for which it was developed. As there is growing evidence that underexposure of MPA is associated with insufficient treatment response, we recommend the introduction of therapeutic drug monitoring for MPA in children with nephrotic syndrome.
\end{abstract}

Keywords Mycophenolic acid · Limited sampling strategy $\cdot$ Nephrotic syndrome $\cdot$ Pharmacokinetics $\cdot$ Therapeutic drug monitoring · Pediatric patients

Electronic supplementary material The online version of this article (https://doi.org/10.1007/s00228-019-02701-5) contains supplementary material, which is available to authorized users.

Joanna Sobiak

jsobiak@ump.edu.pl

1 Department of Physical Pharmacy and Pharmacokinetics, Poznan University of Medical Sciences, 6 Święcickiego Street, 60-781 Poznan, Poland

2 Department of Drug Chemistry, Medical University of Warsaw, 1 Banacha Street, 02-097 Warsaw, Poland

3 Department of Pediatric Cardiology, Nephrology and Hypertension, Poznan University of Medical Sciences, 27/33 Szpitalna Street, 60-572 Poznan, Poland

\section{Introduction}

Nephrotic syndrome, more frequently diagnosed in children, forms a group of clinical symptoms with the proteinuria $[1,2]$. Children with nephrotic syndrome are vulnerable to suffer from many ailments, which may lead to cardiovascular disease, chronic kidney insufficiency, or even to the necessity of renal transplantation $[1,3]$. The treatment of nephrotic syndrome is based on steroids and immunosuppressants [1, 4]; however, long-term steroid therapy unfavorably influences children's development and their further lives $[2,5]$. The immunosuppressants most frequently administered are cyclosporine (CsA), chlorambucil, and cyclophosphamide, which 
cause severe side effects, e.g., hematological, gonadal, and nephrological toxicities [4]. The aim of the treatment is to minimalize the incidence of proteinuria recurrence; however, in some patients, trace proteinuria may be observed, defined as protein concentration $<10 \mathrm{mg} / \mathrm{kg}$ body weight/day, which is rather related to the chronic kidney disease than nephrotic syndrome [6].

Mycophenolate mofetil (MMF), an immunosuppressive drug, is efficient in nephrotic syndrome and does not cause nephrotoxicity and additionally is well tolerated by patients $[1,4]$. MMF is a pro-drug with an active moietymycophenolic acid (MPA). MPA is safe and effective when plasma concentrations are above the target minimum exposure. However, the necessity of monitoring MPA concentration is still a matter of debate. MPA pharmacokinetics is complex and differs between groups of patients what causes difficulties in reaching the target concentrations values. Monitoring MPA $\mathrm{C}_{0}$ would be easy and convenient; however, numerous studies showed that MPA $C_{0}$ poorly correlated with the relapse rate [7]. MPA area under the time-concentration curve from 0 to $12 \mathrm{~h}\left(\mathrm{AUC}_{0-12}\right)$ tends to be a more useful tool in therapeutic drug monitoring (TDM). Still measuring total $\mathrm{AUC}_{0-12}$ is expensive, time-consuming, and inconvenient for patients, especially for children. Moreover, no specific MPA $\mathrm{AUC}_{0-12}$ target was established for children with nephrotic syndrome [8].

Limited sampling strategy (LSS) is a useful approach to assess drug pharmacokinetics and safety. Collecting only few blood samples to establish $\mathrm{AUC}_{0-12}$ is an easier than determining full pharmacokinetic profile. It is more convenient for patients and facilitates the work of nursing staff. There are studies concerning MPA LSS; however, most of them included renal transplant recipients, whereas each LSS should be evaluated and used in the same patient's group [9, 10]. Separate LSS should be evaluated for renal or heart transplant recipients and patients suffering from lupus nephritis or nephrotic syndrome. While there are two main possible calculation methods for evaluating LSS, multiple linear regression (MLR) [11-17] and Bayesian approach [18, 19], there are many software solutions $[18,20,21]$. In this study, we evaluated LSS for children with nephrotic syndrome using two methods of calculation, STATISTICA and R software, and two different methods of validation, validation group and bootstrap method, respectively. We hypothesized that the results obtained using two approaches should be comparable.

\section{Material and methods}

\section{Study population}

The retrospective study included 31 children (13 males and 18 females) with nephrotic syndrome, aged 3-18 years (mean age, 11 years). MMF was administered orally twice a day at the same dose (250-1000 mg) for at least 1 month prior to the pharmacokinetic study. Patients were hospitalized between 2012 and 2015 in Department of Pediatric Cardiology, Nephrology, and Hypertension, University of Medical Sciences in Poznan, Poland. The flow diagram of the patient selection is presented in Fig. 1. For children, demographical data as well as biochemical parameters were recorded.

The blood samples were collected into EDTA tubes before MMF administration $\left(C_{0}\right)$ and subsequently $1 \mathrm{~h}\left(C_{1}\right), 2 \mathrm{~h}\left(C_{2}\right)$, $3 \mathrm{~h}\left(C_{3}\right), 4 \mathrm{~h}\left(C_{4}\right), 6 \mathrm{~h}\left(C_{6}\right), 9 \mathrm{~h}\left(C_{9}\right)$ and $12 \mathrm{~h}\left(C_{12}\right)$ after its administration. MMF was administrated in 12 -h intervals at least for a month before blood collection for pharmacokinetic analysis; therefore, we assumed that all children were in steady state. In 12 children, blood samples were collected up to $6 \mathrm{~h}$; therefore, as they were in steady state, it was assumed that $C_{12}$ was equal to $C_{0}$ [11]. Additionally, we observed that MPA $C_{0}$ and $C_{12}$ were comparable $(2.78 \pm 1.81 \mu \mathrm{g} / \mathrm{mL}$ and $2.07 \pm 0.95 \mu \mathrm{g} / \mathrm{mL}$ for $C_{0}$ and $C_{12}$, respectively, $p=0.055$, $n=25$ ) for those children who had both samples collected. In six children, MPA pharmacokinetic profiles were determined twice after two MMF doses.

Children receiving CsA or MMF at not equal morning and evening doses or shorter than 1 month as well as children with too low number of blood samples collected were excluded from the study.

Four children included in the study received concomitantly steroids and seven children had trace proteinuria $(<10 \mathrm{mg} /$ body weight/day) observed during blood sample collection. These two factors may be the source of potential bias.

Almost all children $(n=35)$ received enalapril and were supplemented with vitamins $\mathrm{A}$ and $\mathrm{E}(n=30)$ as well as alfacalcidol $(n=18)$. Few children received additional antihypertensive drugs (losartanum, amlodipinum; $n=7$ ).

All procedures performed in the studies involving human participants were in accordance with the ethical standards of the institutional and national research committee and with the 1964 Helsinki declaration and its later amendments or comparable ethical standards. The study was approved by the Bioethical Committee at Poznan University of Medical Sciences. Informed consent was obtained from the parents or guardians prior to initiating the study.

\section{Analytical methods}

MPA plasma concentrations were determined using HPLCUV method. The analytical method for MPA determination was described elsewhere $[22,23]$. MPA $\mathrm{AUC}_{0-12}$ was calculated using linear trapezoidal rule and the maximal concentration $\left(C_{\max }\right)$ was extracted from the determined concentrations. To compare the data, we normalized MPA $\mathrm{AUC}_{0-12}$ to the most frequently administered dose which was $500 \mathrm{mg}$ b.i.d. 
Fig. 1 The flow diagram of patient selection. The division into test and validation groups concerns only STATISTICA evaluations. For R evaluations, bootstrap procedure was used. The profiles were randomly divided into test group and validation group, and the procedure was performed 100 times. *Only for STATISTICA evaluations

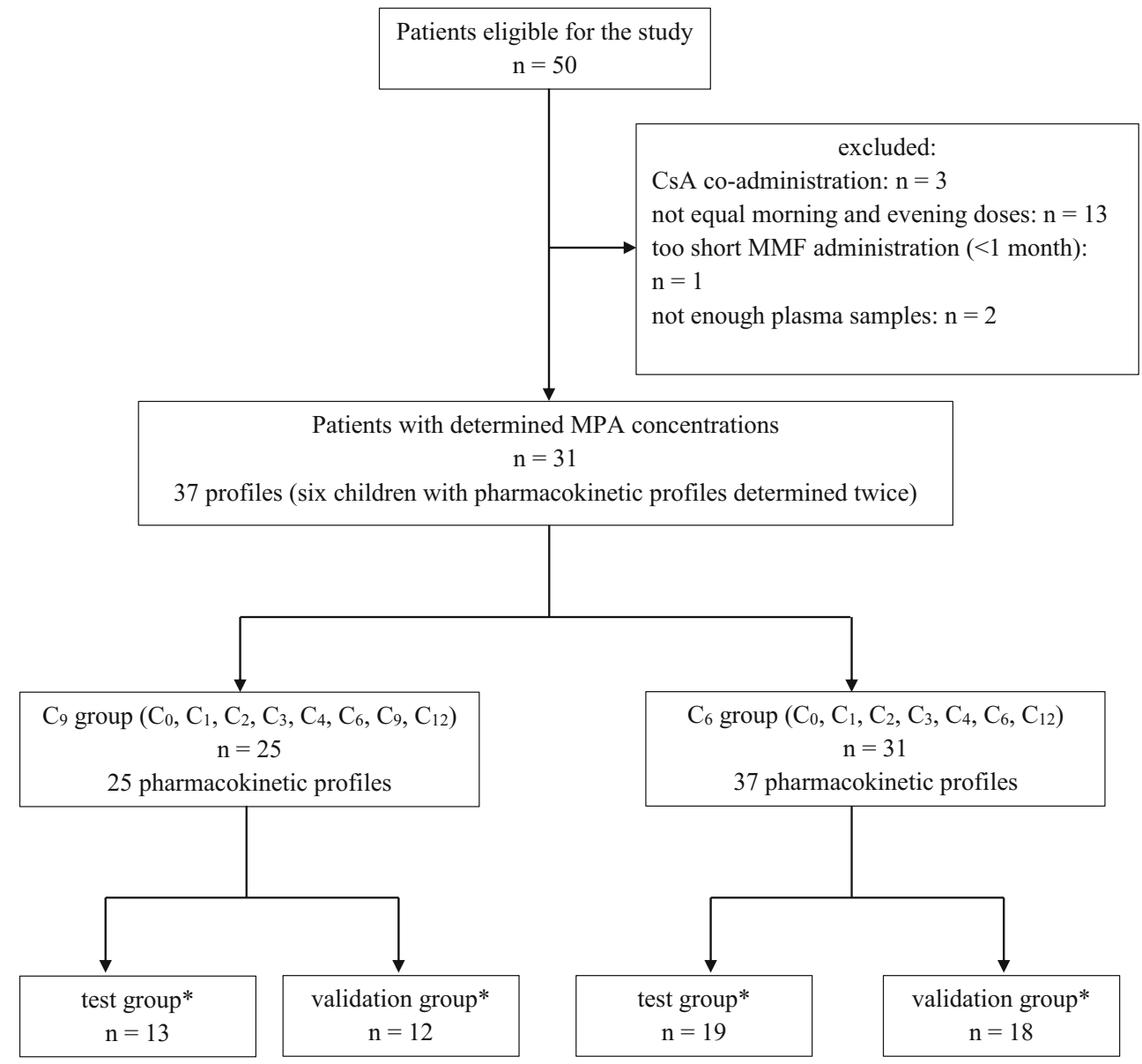

All calculations were performed using MS Excel 2010 (Microsoft Corporation, Redmond, WA, USA).

\section{LSSs evaluation}

For evaluations, two groups with different blood sampling were considered separately. In the first group of children $\left(C_{9}\right.$ group), 25 profiles with the following blood samples $C_{0}, C_{1}$, $C_{2}, C_{3}, C_{4}, C_{6}, C_{9}$, and $C_{12}$ were included, and in the second group of children ( $C_{6}$ group), 37 profiles without $C_{9}$ were included. The six children with MPA profiles determined twice were included in the $C_{6}$ group, and the second profile for each child comprised the validation group. The demographic data were not compared statistically as group $C_{6}$ comprises all patients from group $C_{6}$, and both groups seemed to be very similar. The characteristics are presented in Table 1 .

LSSs were evaluated using STATISTICA 13.0 software (StatSoft, Inc., Tulsa, OK, USA) and R software (R Core Team, 2013). For each measured concentration, calculated $\mathrm{AUC}_{0-12}$ and $C_{\max }$ normal distributions were confirmed using Shapiro-Wilk test (STATISTICA) and Kolmogorov-Smirnov test (R). For both evaluations method, MLR was applied to develop LSSs. The MPA AUC $\mathrm{AO}_{0-12}$ was considered as the dependent variable, while MPA plasma concentrations at each sampling time point were the independent variables. All concentration-time profiles were completed; therefore, no estimation was done. There were no missing data to handle except for missing $C_{12}$ in 12 children, which was previously described $\left(C_{12}\right.$ was assumed to equal $\left.C_{0}\right)$. The equations were evaluated as follows: $\mathrm{AUC}_{\mathrm{pred}}=A+B \times C_{x}+C \times C_{y}+D \times$ $C_{z}$, where $\mathrm{AUC}_{\text {pred }}$ indicated predicted AUC; $A$ indicated the intercept; $C_{x}, C_{y}, C_{z}$ indicated the concentration for three different time points; and $B, C, D$ indicated the coefficients for $C_{x}, C_{y}, C_{z}$, respectively.

For STATISTICA evaluations, children were divided into two groups, test group (13 and 19 MPA profiles for $C_{9}$ and $C_{6}$ group, respectively) and validation group (12 and 18 MPA profiles for $C_{9}$ and $C_{6}$ group, respectively). For test group, the correlations between MPA plasma concentrations at single time points and $\mathrm{AUC}_{0-12}$ were firstly verified. Secondly, the equations were developed using stepwise regression with backward elimination. Finally, the number of possible equations based on samples collected during the first $3 \mathrm{~h}$ after drug administration was calculated according to the formula:

$$
\left(\frac{n}{k}\right)=\frac{n !}{k !(n-k) 1}
$$


Table 1 The characteristics of children included in $C_{9}$ and $C_{6}$ groups (results as means)

\begin{tabular}{lll}
\hline & $C_{9}$ group & $C_{6}$ group \\
\hline No. of patients (male/female) & $25(11 / 14)$ & $31(13 / 18)$ \\
Race (no. of Caucasian/other) & $25 / 0$ & $31 / 0$ \\
Age, years (range) & $10(3-18)$ & $11(3-18)$ \\
Body weight, kg (range) & $36(16-67)$ & $38(15-70)$ \\
Body surface, $\mathrm{m}^{2}$ (range) & $1.2(0.7-1.9)$ & $1.2(0.6-1.9)$ \\
$C_{0} \mathrm{MPA}, \mu \mathrm{g} / \mathrm{mL}$ (range) & $2.78(0.22-7.20)$ & $2.46(0.19-7.20)$ \\
$C_{1} \mathrm{MPA}, \mu \mathrm{g} / \mathrm{mL}$ (range) & $16.68(2.11-44.22)$ & $15.48(2.11-44.22)$ \\
$C_{2} \mathrm{MPA}, \mu \mathrm{g} / \mathrm{mL}$ (range) & $7.14(1.73-17.05)$ & $6.64(0.79-17.05)$ \\
$C_{3} \mathrm{MPA}, \mu \mathrm{g} / \mathrm{mL}$ (range) & $4.04(0.53-12.57)$ & $4.09(0.37-12.57)$ \\
$C_{4} \mathrm{MPA}, \mu \mathrm{g} / \mathrm{mL}$ (range) & $3.12(0.37-6.92)$ & $3.06(0.30-6.92)$ \\
$C_{6} \mathrm{MPA}, \mu \mathrm{g} / \mathrm{mL}$ (range) & $2.81(0.42-7.88)$ & $2.77(0.25-7.88)$ \\
$C_{9} \mathrm{MPA}, \mu \mathrm{g} / \mathrm{mL}$ (range) & $2.47(0.38-6.79)$ & \\
$C_{12} \mathrm{MPA}, \mu \mathrm{g} / \mathrm{mL}$ (range) & $2.07(0.53-3.84)$ & $1.98(0.19-3.84)$ \\
AUC ${ }_{0-12} \mathrm{MPA}, \mu \mathrm{g}$ h/mL (range) & $54.43(9.31-95.88)$ & $49.07(7.19-94.54)$ \\
MPA $t_{\text {max }}, \mathrm{h}$ & $1(1-3)^{\mathrm{a}}$ & $1(1-3)^{\mathrm{a}}$ \\
No. of valid profiles & 25 & $37^{\mathrm{b}}$ \\
MMF dose $(0.25 / 0.3 / 0.35 / 0.4 / 0.5 / 0.6 / 0.75 / 1 \mathrm{~g}$ twice a & $3 / 1 / 1 / 1 / 10 / 1 / 7 / 1$ & $5 / 1 / 1 / 1 / 18 / 1 / 9 / 1$ \\
day) & profiles & profiles \\
MMF usage period, months (range) & $11(2-29)$ & $9(1-29)$ \\
\hline
\end{tabular}

${ }^{\text {a }}$ Median (range)

${ }^{\mathrm{b}}$ Six children (three boys, three girls) had MPA profiles determined twice where $k$ is the number of $k$-combinations (for equations with up to three time points) and $n$ is the number of elements in the set $\left(C_{0}, C_{1}, C_{2}, C_{3} ; 4\right.$ elements). Subsequently, each of the possible 14 combinations was introduced manually into the software. Each developed equation was used for calculating $\mathrm{AUC}_{\text {pred }}$ for children in the validation group.

For $\mathrm{R}$ evaluations, it was assumed that the model should include up to three time points. For $C_{6}$ and $C_{9}$ groups, the profiles were randomly divided into two groups (test group and validation group). This procedure was performed 100 times to obtain the most varied and random test and validation groups (bootstrap procedure). Based on the results from test groups, all possible models were assessed. For each model, $\mathrm{AUC}_{\text {pred }}$ were calculated using coefficients which were medians from the previously calculated 100 coefficients. $\mathrm{AUC}_{\text {pred }}$ were calculated for all profiles because all profiles were previously used for building models.

For both evaluation methods, we calculated the values of $r^{2}$, adjusted $r^{2}$, good guess, and root square mean error (RMSE) for each equation to analyze the agreement between $\mathrm{AUC}_{\text {pred }}$ and $\mathrm{AUC}_{\text {calc. }}$. Good guess was determined by the number of profiles for $\mathrm{AUC}_{\text {pred }}$ within $\mathrm{AUC}_{0-12} \pm$ $15 \%$. The bias and precision for predicting $\mathrm{AUC}_{0-12}$ was assessed based on mean prediction error (\%MPE) and mean absolute error (\%MAE), respectively. The accepted values for $\% \mathrm{MPE}$ and $\% \mathrm{MAE}$ were $\pm 15 \%$ and $\pm 10 \%$, respectively [24]. The best model was chosen on the base of good guess, $r^{2}$, and adjusted $r^{2}$.

\section{Results}

\section{Pharmacokinetic parameters}

For all children included in the study, MPA concentrations from 0 to $12 \mathrm{~h}$ and $\mathrm{AUC}_{0-12}$ are presented in Table 1. MPA $\mathrm{AUC}_{0-12}$ was within $9.31 \mu \mathrm{g} \mathrm{h} / \mathrm{mL}$ and $95.88 \mu \mathrm{g} \mathrm{h} / \mathrm{mL}$ for $\mathrm{C}_{9}$ group and within $7.19 \mu \mathrm{g} \mathrm{h} / \mathrm{mL}$ and $94.54 \mu \mathrm{g} \mathrm{h} / \mathrm{mL}$ for $\mathrm{C}_{6}$ group. MPA AUC ${ }_{0-12}$ below $10 \mu \mathrm{g} \mathrm{h} / \mathrm{mL}$ was observed in three children receiving MMF dose of $250 \mathrm{mg}$ b.i.d. The dose-normalized MPA $\mathrm{AUC}_{0-12}$ was within $18.62 \mu \mathrm{g} \mathrm{h} / \mathrm{mL}$ and $92.95 \mu \mathrm{g} \mathrm{h} / \mathrm{mL}$ for $\mathrm{C}_{9}$ group and within $12.65 \mu \mathrm{g} \mathrm{h} / \mathrm{mL}$ and $131.56 \mu \mathrm{g} \mathrm{h} / \mathrm{mL}$ for $\mathrm{C}_{6}$ group. Mean MPA $\mathrm{AUC}_{0-12}$ was lower in children with proteinuria $(43.80 \pm 33.26 \mu \mathrm{g} \mathrm{h} / \mathrm{mL}$ vs. $50.30 \pm 18.53 \mu \mathrm{g} \mathrm{h} / \mathrm{mL}$ for children with and without proteinuria, respectively); however, the difference was not significant. Only one child with proteinuria had MPA $\mathrm{AUC}_{0-12}$ below $10 \mu \mathrm{g} \mathrm{h} / \mathrm{mL}$. This child may have received too low MMF dose or may have not response to MMF. For six children with MPA AUC ${ }_{0-12}$ above $10 \mu \mathrm{g} \mathrm{h} / \mathrm{mL}$, proteinuria may have been related to the chronic kidney disease with tissue proteinuria without the nephrotic syndrome and concomitant edema and coagulant disorders. 


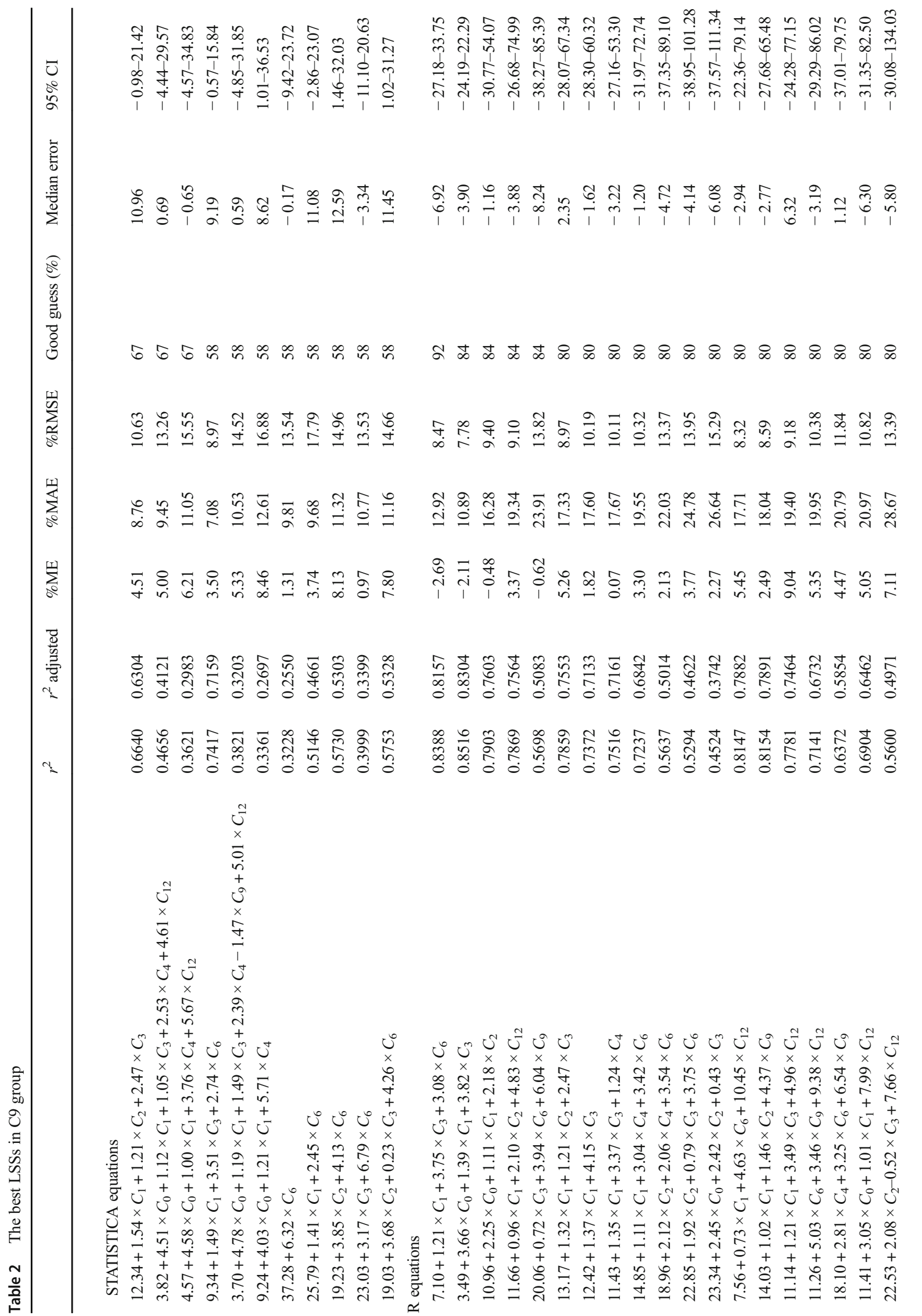


Table 3 The best LSSs in $C_{6}$ group

$\begin{array}{llllll}r^{2} & \begin{array}{l}r^{2} \\ \text { adjusted }\end{array} & \% \text { ME } & \% \text { MAE } \% \text { RMSE } \begin{array}{l}\text { Good guess } \\ (\%)\end{array} & \begin{array}{l}\text { Median } \\ \text { error }\end{array} & 95 \% \text { CI }\end{array}$

\begin{tabular}{|c|c|c|c|c|c|c|c|c|}
\hline \multicolumn{9}{|l|}{ STATISTICA equations } \\
\hline $\begin{array}{l}1.62+2.22 \times C_{0}+1.27 \times C_{1}+2.32 \times C_{3}+1.32 \times C_{4} \\
\quad+3.07 \times C_{6}\end{array}$ & 0.9477 & 0.9444 & -0.39 & 2.87 & 3.92 & 94 & -0.33 & $-3.09-3.86$ \\
\hline $2.08+1.85 \times C_{0}+1.28 \times C_{1}+2.88 \times C_{3}+3.67 \times C_{6}$ & 0.9289 & 0.9244 & -1.43 & 3.57 & 4.70 & 89 & -0.78 & $-5.65-2.79$ \\
\hline $2.55+1.28 \times C_{1}+2.98 \times C_{3}+4.76 \times C_{6}$ & 0.8838 & 0.8765 & -2.78 & 4.66 & 6.20 & 83 & -1.19 & $-9.85-0.46$ \\
\hline $2.87+0.81 \times C_{1}+2.74 \times C_{2}+5.69 \times C_{6}$ & 0.8542 & 0.8451 & 0.72 & 5.76 & 7.28 & 72 & 2.27 & $-5.33-7.69$ \\
\hline $12.67+1.19 \times C_{1}+6.38 \times C_{6}$ & 0.7504 & 0.7348 & -0.57 & 6.79 & 8.31 & 72 & -1.71 & $-8.15-10.27$ \\
\hline $2.71+1.36 \times C_{1}+1.39 \times C_{2}+5.60 \times C_{4}$ & 0.7246 & 0.7074 & 2.05 & 7.56 & 10.08 & 72 & 1.60 & $-4.92-13.01$ \\
\hline $\begin{array}{l}1.37+4.66 \times C_{0}+1.39 \times C_{1}-0.14 \times C_{2}+1.64 \times C 3 \\
\quad+3.30 \times C_{4}\end{array}$ & 0.7101 & 0.6920 & 2.40 & 7.79 & 9.28 & 72 & 7.14 & $-1.87-15.17$ \\
\hline $1.27+4.59 \times C_{0}+1.37 \times C_{1}+1.46 \times C_{3}+3.46 \times C_{4}$ & 0.7197 & 0.7022 & 2.60 & 7.68 & 9.21 & 72 & 7.44 & $-1.47-15.31$ \\
\hline \multicolumn{9}{|l|}{$\mathrm{R}$ equations } \\
\hline $3.59+1.25 \times C_{1}+3.06 \times C_{3}+4.65 \times C_{6}$ & 0.9522 & 0.9479 & 1.20 & 9.19 & 4.72 & 89 & 1.56 & $-19.70-33.78$ \\
\hline $5.81+0.97 \times C_{1}+2.20 \times C_{2}+4.69 \times C_{6}$ & 0.9353 & 0.9295 & 3.14 & 12.12 & 5.47 & 84 & 1.23 & $-18.04-51.55$ \\
\hline $2.39+3.97 \times C_{0}+1.44 \times C_{1}+3.38 \times C_{3}$ & 0.9017 & 0.8928 & 0.57 & 11.93 & 6.75 & 84 & -2.34 & $-19.38-31.92$ \\
\hline $6.32+1.18 \times C_{1}+3.87 \times C_{4}+4.50 \times C_{6}$ & 0.9111 & 0.9030 & 4.79 & 14.48 & 6.36 & 81 & 2.39 & $-21.28-53.71$ \\
\hline $6.09+1.48 \times C_{1}+2.46 \times C_{3}+2.86 \times C_{4}$ & 0.8438 & 0.8296 & 3.05 & 15.44 & 8.52 & 81 & 1.21 & $-31.76-50.82$ \\
\hline $9.78+2.45 \times C_{2}+2.00 \times C_{4}+5.85 \times C_{6}$ & 0.7864 & 0.7670 & 6.66 & 20.12 & 9.88 & 81 & 2.34 & $-35.15-90.49$ \\
\hline $5.43+0.90 \times C_{1}+5.11 \times C_{6}+7.33 \times C_{12}$ & 0.9097 & 0.9015 & 2.93 & 14.87 & 6.51 & 81 & -0.48 & $-26.75-46.08$ \\
\hline $5.98+3.67 \times C_{0}+1.20 \times C_{1}+2.25 \times C_{2}$ & 0.8473 & 0.8334 & 4.26 & 15.63 & 8.35 & 78 & 1.47 & $-31.66-42.90$ \\
\hline $5.12+2.00 \times C_{2}+5.77 \times C_{6}+7.19 \times C_{12}$ & 0.8504 & 0.8369 & 4.07 & 14.78 & 8.26 & 78 & 2.44 & $-30.44-54.95$ \\
\hline
\end{tabular}

\section{LSSs equations}

The best equations for both evaluations methods are presented in Tables 2 and 3. Some of the other LSSs are included in Tables A.1 and B.1 (Appendices A and B).

For evaluations with STATISTICA software 53 and 48 equations in total, consisting of one up to seven concentration time points were obtained for $C_{9}$ and $C_{6}$ groups, respectively. For evaluations with $\mathrm{R}$ software, each model composed of one, two, or three time points and 92 models and 63 models were obtained in total for $C_{9}$ group and $C_{6}$ group, respectively.

For STATISTICA calculations, firstly, the equations included more than three time points. In total for both groups $\left(C_{6}\right.$ and $\left.C_{9}\right)$, there were one equation with six time points, four with five time points, and four with four time points (Tables 2 and 3; Table A.1). The best $r^{2}$, adjusted $r^{2}$, and good guess (94\%) were for the equation including $C_{0}, C_{1}, C_{3}, C_{4}, C_{6}$ for $C_{6}$ group. The appropriate good guess (89\%), $r^{2}$, and adjusted $r^{2}(>0.900)$ were obtained for four time point equation $\left(C_{0}\right.$, $C_{1}, C_{3}, C_{6}$ ) for $C_{6}$ group. The equation with six time points $\left(C_{0}, C_{1}, C_{3}, C_{4}, C_{9}, C_{12}\right)$ should be precise; however, its good guess amounted to only $58 \%$.

For the $C_{9}$ group and equations with three time points, three best equations included $C_{1}, C_{2}, C_{3} ; C_{1}, C_{3}, C_{6}$; and $C_{0}, C_{1}, C_{4}$ for STATISTICA software; however, the good guess values were rather poor for these equations $(67 \%, 58 \%, 50 \%$, respectively; Table 2). For R software, three best equations consisted of $C_{1}, C_{3}, C_{6} ; C_{0}, C_{1}, C_{3}$; and $C_{0}, C_{1}, C_{2}$. Good guess was $>80 \%$ for five best equations evaluated with $\mathrm{R}$, whereas for STATISTICA evaluations, the highest good guest amounted to $67 \%$. The values of $r^{2}$ and adjusted $r^{2}$ for $\mathrm{R}$ evaluations were $>0.800$ for two best equations and for one equation $\left(C_{1}, C_{4}, C_{9}\right)$ with good guess $72 \%$. The values of $r^{2}$

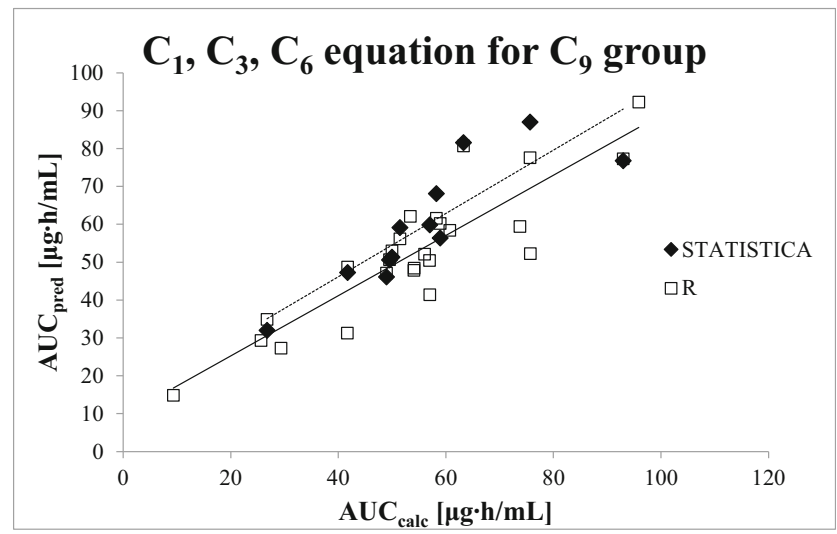

Fig. 2 The correlations between $\mathrm{AUC}_{\text {pred }}$ derived from $C_{1}, C_{3}, C_{6}$, and $\mathrm{AUC}_{\text {calc }}$ from 0 to $12 \mathrm{~h}$ MPA pharmacokinetic profile in $C_{9}$ group. The equations including $C_{1}, C_{3}$, and $C_{6}$ were evaluated with STATISTICA (closed diamonds; dotted line) and $\mathrm{R}$ (open squares; solid line). The equations were $9.34+1.49 \cdot C_{1}+3.51 \cdot C_{3}+2.74 \cdot C_{6}$ for STATISTICA and $7.10+1.21 \cdot C_{1}+3.75 \cdot C_{3}+3.08 \cdot C_{6}$ for $\mathrm{R}$ 
and good guess were better for the equations evaluated with $\mathrm{R}$ software, whereas \%MAE was lower for STATISTICA evaluations (Table 2; Table A.1). In Fig. 2, we compared the correlations between $\mathrm{AUC}_{\text {pred }}$ and $\mathrm{AUC}_{\text {calc }}$ for the best equation $\left(C_{1}, C_{3}, C_{6}\right)$ estimated with STATISTICA and $\mathrm{R}$ in $C_{9}$ group.

For $C_{6}$ group and STATISTICA, the best three time point equations included $C_{1}, C_{3}, C_{6}$ (with the best good guess, i.e., $83 \%) ; C_{1}, C_{2}, C_{6}$; and $C_{1}, C_{2}, C_{4}$. For R software, three best equations included $C_{1}, C_{3}, C_{6}$ (with the best good guess, i.e., $89 \%$ ); $C_{1}, C_{2}, C_{6}$; and $C_{0}, C_{1}, C_{3}$. For STATISTICA evaluations, two equations with three time-points were characterized by $r^{2}$ and adjusted $r^{2}>0.800$ with good guess $83 \%$ and $72 \%$. For R evaluations, good guess for seven equations was $>80 \%$. The values of $r^{2}$ and adjusted $r^{2}$ were $>0.900$ for four equations. For the $C_{6}$ group, the values of $r^{2}$, adjusted $r^{2}$, and good guess were also better for the evaluations with $\mathrm{R}$ software; however, the differences were smaller than within $C_{9}$ group for some equations as well as \%MPE, \%MAE, and median error were lower for STATISTICA evaluations (Table 3). In Fig. 3, we compared the correlations between $\mathrm{AUC}_{\text {pred }}$ and $\mathrm{AUC}_{\text {calc }}$ for the best equation $\left(C_{1}, C_{3}, C_{6}\right)$ estimated with STATISTICA and $\mathrm{R}$ in $C_{6}$ group.

The best equations with two time points included $C_{1}, C_{6}$ for both groups and STATISTICA calculations, whereas for R calculations, $C_{1}, C_{3}$ and $C_{1}, C_{6}$ were the best for $C_{9}$ and $C_{6}$ groups, respectively. The good guess values were better for the $\mathrm{R}$ results (Tables 2 and 3 ).

For one time point equation, the highest good guess was $72 \%\left(C_{1}\right)$ for $\mathrm{R}$ evaluations and $58 \%\left(C_{6}\right)$ for STATISTICA for $C_{9}$ group (Table 2; Table A.1). For $C_{6}$ group, the best good guess was $68 \%\left(C_{1}\right)$ and $50 \%\left(C_{1}\right)$ for $\mathrm{R}$ and STATISTICA, respectively (data not shown). In $C_{9}$ group, the one time point equation with $C_{0}$ was characterized by the good guess of $72 \%$ for $\mathrm{R}$ calculations but only of $17 \%$ for STATISTICA (data not

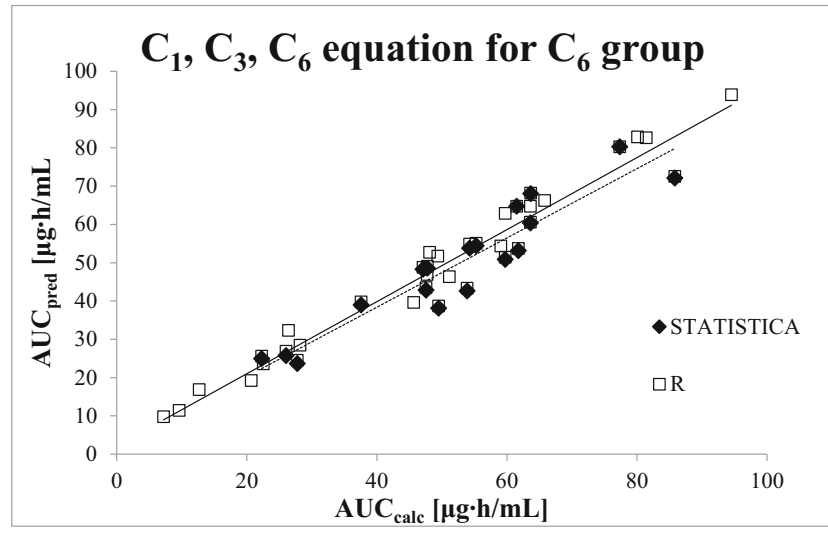

Fig. 3 The correlations between $\mathrm{AUC}_{\text {pred }}$ derived from $C_{1}, C_{3}, C_{6}$, and $\mathrm{AUC}_{\text {calc }}$ from 0 to $12 \mathrm{~h}$ MPA pharmacokinetic profile in $C_{6}$ group. The equations including $C_{1}, C_{3}$, and $C_{6}$ were evaluated with STATISTICA (closed diamonds; dotted line) and $\mathrm{R}$ (open squares; solid line). The equations were $2.55+1.28 \cdot C_{1}+2.98 \cdot C_{3}+4.76 \cdot C_{6}$ for STATISTICA and $3.59+1.25 \cdot C_{1}+3.06 \cdot C_{3}+4.65 \cdot C_{6}$ for $\mathrm{R}$ shown). For $C_{6}$ group, the good guess for $C_{0}$ equations amounted to $62 \%$ for R and $28 \%$ for STATISTICA (data not shown).

Among the best 47 equations presented in Tables 2 and 3, about $41 \%$ (14/47) included $C_{0}$.

\section{Discussion}

The MPA pharmacokinetic parameters are highly variable, and there are numerous factors which may contribute to this variability, e.g., treatment duration, therapeutic indication, drugs co-administered, genetic, physiologic, and environmental factors, as well as kidney or liver dysfunction [8]. For TDM, MPA $\mathrm{AUC}_{0-12}$ is the most useful parameter; however, obtaining full pharmacokinetic profile is time-consuming and inconvenient for patients, especially for children [25], and there is still a need to establish target values for children with nephrotic syndrome [8]. In our previous study [22], we suggested that for those children, MPA $\mathrm{AUC}_{0-12}>60 \mu \mathrm{g} \mathrm{h} / \mathrm{mL}$ may be considered efficient to avoid proteinuria recurrence and ensure the safe and effective treatment. Moreover, we did not observe any toxicity in those children. Other studies showed that MPA AUC ${ }_{0-12}$ above $30 \mu \mathrm{g} \mathrm{h} / \mathrm{mL}$ is recommended for children with nephrotic syndrome [26] or described fewer relapses in children with $\mathrm{MPA} \mathrm{AUC}_{0-12}$ above $45 \mu \mathrm{g} \mathrm{h} / \mathrm{mL}$ [8]. However, there are some cases where MMF is ineffective when standard doses are administered. The recent study of Kirpalani et al. [27] described the increase in MPA apparent clearance which may indicate that the unresponsiveness of MMF may be due to MPA underexposure. Therefore, it seems important to find if the reason why children do not respond to MMF is dose-related (infra or over dosing) and if so correct the dose before changing the treatment to other drugs with severe adverse effects (such as CsA or cyclophosphamide) in these children. The evaluation of MPA LSS should facilitate assessing treatment efficacy in pediatric patients.

There are two main approaches to evaluate LSS, Bayesian estimation and MLR, which can be performed using several software programs. NONMEM, a nonlinear mixed-effect modeling tool, is the gold standard for population pharmacokinetic analysis. However, working with this program is difficult because NONMEM is written in Fortran language [20, 21]. Therefore, we decided to evaluate and compare the LSSs using other software, STATISTICA and R. Both programs rely on MLR as computation methods. R software comprises powerful statistical techniques, supports object-oriented programming, and its accessible free of charge [20]. The STATISTICA line of software consists of a fully integrated line of analytic solutions which are easy to handle and offer wide options of algorithms, functions, and tests as well as effective graphic visualization. 


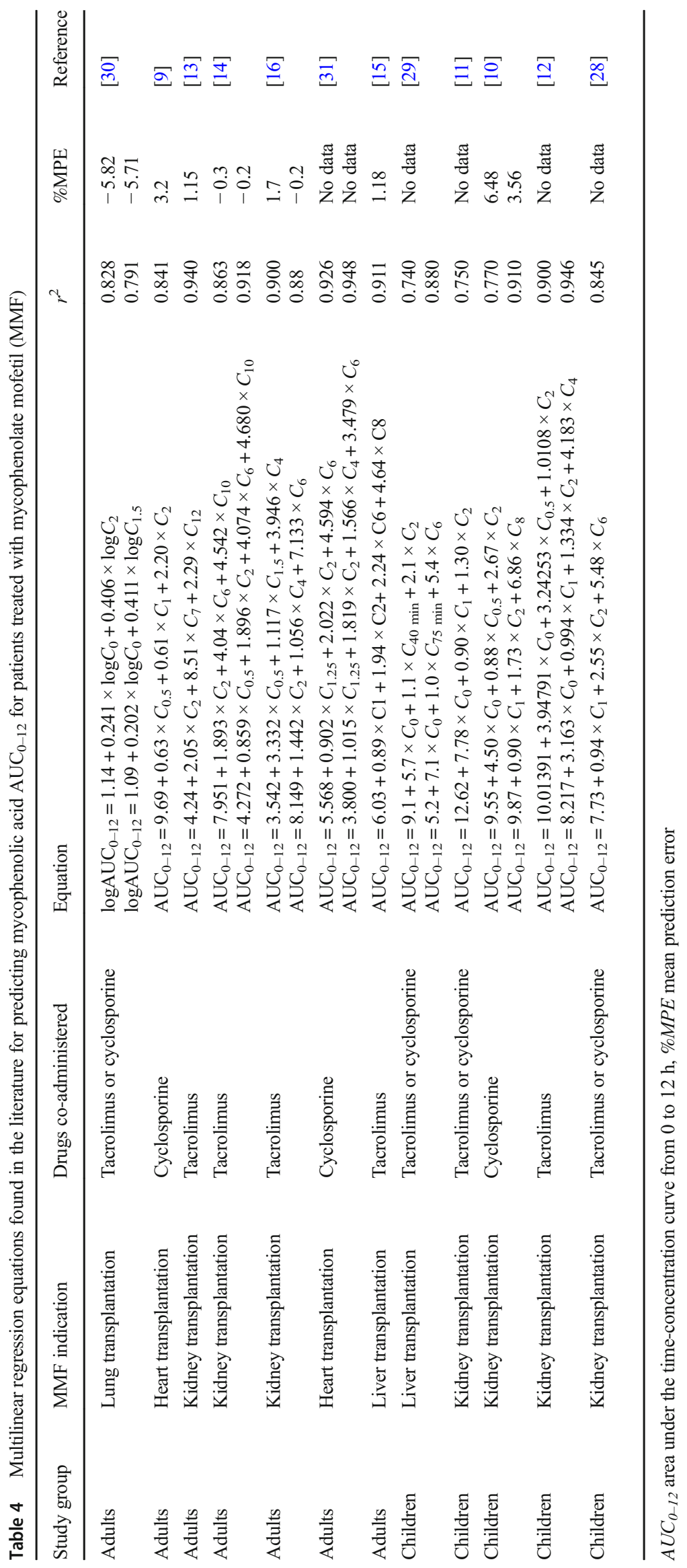


To our knowledge, in the literature, there are only a few studies concerning LSS as the approach for monitoring MPA therapy in children and adults with nephrotic syndrome. In none of the studies, MLR method was applied for evaluations. Saint-Marcoux et al. [18] and Zhao et al. [19] evaluated LSS for children with nephrotic syndrome basing on Bayesian estimator method. Some LSS for MMF treated patients evaluated using MLR concerned pediatric patients after renal [10-12, $28]$ or liver $[15,29]$ transplantation as well as adults patients after renal [13, 14, 16], lung [30], heart [9, 31], and liver [15] transplantation. The equations from these studies are shown in Table 4.

We assumed that it would be the most convenient procedure for patients if the LSS evaluated includes up to three time points. Therefore, the equations with four to six time points, generated with STATISTICA, although characterized by the best good guess (up to 94\%) will not be useful in clinical practice. The most convenient approach for patients would be collecting only one or two blood samples; however, in our study, the results obtained for these equations were not satisfactory comparing with the three time point equations.

The best three time point equations in our study included $C_{1}, C_{3}, C_{6} ; C_{1}, C_{2}, C_{6}$; and $C_{1}, C_{2}, C_{4}$ for evaluations with STATISTICA software and $C_{1}, C_{3}, C_{6} ; C_{1}, C_{2}, C_{6} ; C_{0}, C_{1}, C_{2}$; and $C_{0}, C_{1}, C_{3}$ for evaluations with $\mathrm{R}$ software. The same time points were included in the best equation for $\mathrm{R}$ calculations for both $\left(C_{6}\right.$ and $\left.C_{9}\right)$ groups. The literature data with LSS for pediatric patients included $C_{20}$ min,$C_{60}$ min,$C_{180 \text { min }}$ [18], or $C_{0}, C_{1}, C_{4}$ [19]; however, these LSS were evaluated based on Bayesian estimator. Among MLR equations found in the literature, not only none of them included $C_{1}, C_{2}, C_{3}$ and $C_{1}, C_{3}$, $C_{6}$ time points, but also none of them considered children with nephrotic syndrome. Therefore, we suggest that LSS should be validated and used only in the population for which it was developed. It is in accordance with our previous data [22] as we concluded that MPA pharmacokinetic parameters must be calculated and applied separately for patients after renal transplantation and with nephrotic syndrome. The differences may derive from the MPA pharmacokinetic intra- and intervariability.

Apart from including three time points, the most useful equations should also contain time points collected up to $3 \mathrm{~h}$ after drug administration because most of the children are not hospitalized but treated in clinics. Therefore, although $C_{1}, C_{3}, C_{6}$ comprised the best equation, collecting $C_{0}, C_{1}, C_{3}$ or $C_{0}, C_{1}, C_{2}$ should be more practical. However, this approach in the case of MPA may lead to misprediction of $\mathrm{AUC}_{0-12}$ due to MPA enterohepatic recirculation and the occurrence of MPA second $C_{\max }$. According to the literature, the most accurate LSS should probably include at least one blood sample collected at time point close to second $C_{\max }$ of MPA due to MPA enterohepatic recirculation [32].
In our study, only a few equations included $C_{0}$ which is in accordance with the literature data as MPA $C_{0}$ did not predict the response to the drug sufficiently [9].

In general, the results obtained using STATISTICA and R were different and better for R. Apart from two best three time point equations for $C_{6}$ group which are the same, the subsequent equations differ. The best equation for $C_{9}$ group for STATISTICA $\left(C_{1}, C_{2}, C_{3}\right)$ is the sixth for R calculations. The second best equation for STATISTICA $\left(C_{1}, C_{3}, C_{6}\right)$ is the best for R. Better values of $r^{2}$, adjusted $r^{2}$, and good guess were obtained for LSS generated with R program. The difference may be explained by different validations for both computing methods. At the same time, \%MPE and \%MAE were lower for STATISTICA results. The difference is smaller for $C_{6}$ group as this group was more numerous. The greater number of patients contributed to the better results for STATISTICA in $C_{6}$ group than $C_{9}$ group. We assumed that test group and validation group should be more numerous to achieve better results with STATISTICA.

The limitation of our study is the fact that we were unable to collect the samples more frequently, especially within the first $2 \mathrm{~h}$ after MMF administration. More studies on the larger number of pediatric patients are needed to confirm our observations. Other limitations are the inclusion of only Caucasian children, children receiving steroids, and children with trace proteinuria during the day of blood collection. These factors may influence MPA exposure and limit the generalizability of the study.

\section{Conclusion}

The best equations in our study included $C_{1}, C_{3}, C_{6} ; C_{0}, C_{1}$, $C_{3}$; and $C_{0}, C_{1}, C_{2}$. The most useful in everyday practice equations include $C_{0}, C_{1}, C_{3}$ and $C_{0}, C_{1}, C_{2}$; however, the most precise is the equation including $C_{1}, C_{3}, C_{6}$ time points. Better results were obtained with $\mathrm{R}$ software.

For validation method, the number of patients is essential; therefore, better results were obtained with $\mathrm{R}$ calculations and the bootstrap validation as validation groups for STATISTICA calculations were smaller.

The proposed equations may be an useful implement for MPA monitoring in children with nephrotic syndrome treated with MMF as there is growing evidence that underexposure of MPA is associated with insufficient treatment response. Still, it is important to remember that properly validated LSS should be used only in the population for which it was developed.

Acknowledgments The authors would like to acknowledge the nursing staff that participated in the sample collection.

Authors' individual contributions JS, TP, DO-N, and MC designed the study; JS, MR, DO-N, and JZ collected the data; JS and MR carried out the quantifications of analytes in blood; JS, TP, and PŻ carried out the 
statistical analyses; JS, TP, and MC analyzed data; and JS and TP wrote the first draft of the manuscript. All authors contributed to, and have approved, the final manuscript.

Funding This study was financially supported by Poznan University of Medical Sciences, Poland (grant number 502-14-03306413-10156).

\section{Compliance with ethical standards}

The study was approved by the Bioethical Committee at Poznan University of Medical Sciences.

Conflict of interest The authors declare that they have no conflict of interest.

Informed consent Informed consent to participate was obtained from all parents or guardians of individual participants included in the study.

Ethical approval All procedures performed in studies involving human participants were in accordance with the ethical standards of the institutional and/or national research committee and with the 1964 Helsinki declaration and its later amendments or comparable ethical standards.

Open Access This article is distributed under the terms of the Creative Commons Attribution 4.0 International License (http:// creativecommons.org/licenses/by/4.0/), which permits unrestricted use, distribution, and reproduction in any medium, provided you give appropriate credit to the original author(s) and the source, provide a link to the Creative Commons license, and indicate if changes were made.

\section{References}

1. Ostalska-Nowicka D, Malinska A, Silska M, Perek B, Zachwieja J, Nowicki M (2011) Mycophenolate mofetil (MMF) treatment efficacy in children with primary and secondary glomerulonephritis. Arch Med Sci AMS 7:1042-1048. https://doi.org/10.5114/aoms. 2011.26618

2. Guha P, De A, Ghosal M (2009) Behavior profile of children with nephrotic syndrome. Indian J Psychiatry 51:122-126. https://oi. org/10.4103/0019-5545.49452

3. Cadnapaphornchai MA, Tkachenko O, Shchekochikhin D, Schrier RW (2014) The nephrotic syndrome: pathogenesis and treatment of edema formation and secondary complications. Pediatr Nephrol 29: 1159-1167. https://doi.org/10.1007/s00467-013-2567-8

4. Lombel RM, Gipson DS, Hodson EM (2013) Treatment of steroidsensitive nephrotic syndrome: new guidelines from KDIGO. Pediatr Nephrol 28:415-426. https://doi.org/10.1007/s00467-0122310-x

5. Tönshoff B, Höcker B, Weber LT (2005) Steroid withdrawal in pediatric and adult renal transplant recipients. Pediatr Nephrol 20: 409-417. https://doi.org/10.1007/s00467-004-1765-9

6. Noone DG, Iijima K, Parekh R (2018) Idiopathic nephrotic syndrome in children. Lancet 392:61-74. https://doi.org/10.1016/ S0140-6736(18)30536-1

7. Hackl Á, Cseprekál O, Gessner M, Liebau MC, Habbig S, Ehren R, Müller C, Taylan C, Dötsch J, Weber LT (2016) Mycophenolate mofetil therapy in children with idiopathic nephrotic syndrome: does therapeutic drug monitoring make a difference? Ther Drug Monit 38:274-279. https://doi.org/10.1097/FTD.0000000000000258

8. Tellier S, Dallocchio A, Guigonis V, Saint-Marcoux F, Llanas B, Ichay L, Bandin F, Godron A, Morin D, Brochard K, Gandia P,
Bouchet S, Marquet P, Decramer S, Harambat J (2016) Mycophenolic acid pharmacokinetics and relapse in children with steroid-dependent idiopathic nephrotic syndrome. Clin J Am Soc Nephrol 11:1777-1782. https://doi.org/10.2215/CJN.00320116

9. Pawinski T, Kunicki PK, Sobieszczanska-Malek M, Gralak B, Szlaska I (2009) A limited sampling strategy for estimating mycophenolic acid area under the curve in adult heart transplant patients treated with concomitant cyclosporine. J Clin Pharm Ther 34:89 101. https://doi.org/10.1111/j.1365-2710.2008.00973.x

10. Weber LT, Hoecker B, Armstrong VW, Oellerich M, Tönshoff B (2006) Validation of an abbreviated pharmacokinetic profile for the estimation of mycophenolic acid exposure in pediatric renal transplant recipients. Ther Drug Monit 28:623-631. https://doi.org/10. 1097/01.ftd.0000246766.12872.12

11. David-Neto E, Araujo LMP, Sumita NM et al (2003) Mycophenolic acid pharmacokinetics in stable pediatric renal transplantation. Pediatr Nephrol 18:266-272. https://doi.org/10.1007/s00467-002-1057-1

12. Filler G (2004) Abbreviated mycophenolic acid AUC from CO, C1, $\mathrm{C} 2$, and $\mathrm{C} 4$ is preferable in children after renal transplantation on mycophenolate mofetil and tacrolimus therapy. Transpl Int 17:120 125. https://doi.org/10.1111/j.1432-2277.2004.tb00415.x

13. Teshima D, Maiguma T, Kaji H, Otsubo K, Kitagawa N, Okabe Y, Sugitani A, Tanaka M, Oishi R (2008) Estimation of the area under the curve for mycophenolic acid in adult renal transplant patients with concomitant tacrolimus using a limited sampling strategy. J Clin Pharm Ther 33:159-163. https://doi.org/10.1111/j.13652710.2008.00896.x

14. Cai W, Ye C, Sun X, Qin K, Qin Y, Zhao D, Wu F, Hu Y, Li H, Tan L (2015) Limited sampling strategy for predicting area under the concentration-time curve for mycophenolic acid in Chinese adults receiving mycophenolate mofetil and tacrolimus early after renal transplantation. Ther Drug Monit 37:304-310. https://doi.org/10. 1097/FTD.0000000000000165

15. Zicheng Y, Weixia Z, Hao C, Hongzhuan C (2007) Limited sampling strategy for the estimation of mycophenolic acid area under the plasma concentration-time curve in adult patients undergoing liver transplant. Ther Drug Monit 29:207-214. https://doi.org/10. 1097/FTD.0b013e318040ce0b

16. Cai W, Cai Q, Xiong N, Qin Y, Lai L, Sun X, Hu Y (2018) Limited sampling strategy for estimating mycophenolic acid exposure on day 7 post-transplant for two mycophenolate mofetil formulations derived from 20 Chinese renal transplant recipients. Transplant Proc 50:1298-1304. https://doi.org/10.1016/j.transproceed.2018. 02.068

17. Brooks EK, Tett SE, Isbel NM, McWhinney B, Staatz CE (2018) Evaluation of multiple linear regression-based limited sampling strategies for enteric-coated mycophenolate sodium in adult kidney transplant recipients. Ther Drug Monit 40:195-201. https://doi.org/ 10.1097/FTD.0000000000000486

18. Saint-Marcoux F, Guigonis V, Decramer S, Gandia P, Ranchin B, Parant F, Bessenay L, Libert F, Harambat J, Bouchet S, Broux F, Compagnon P, Marquet P (2011) Development of a Bayesian estimator for the therapeutic drug monitoring of mycophenolate mofetil in children with idiopathic nephrotic syndrome. Pharmacol Res 63: 423-431. https://doi.org/10.1016/j.phrs.2011.01.009

19. Zhao W, Elie V, Baudouin V, Bensman A, André JL, Brochard K, Broux F, Cailliez M, Loirat C, Jacqz-Aigrain E (2010) Population pharmacokinetics and Bayesian estimator of mycophenolic acid in children with idiopathic nephrotic syndrome. Br J Clin Pharmacol 69:358-366. https://doi.org/10.1111/j.1365-2125.2010.03615.x

20. Li J, Yan K, Hou L, du X, Zhu P, Zheng L, Zhu C (2017) An algorithm and $\mathrm{R}$ program for fitting and simulation of pharmacokinetic and pharmacodynamic data. Eur J Drug Metab Pharmacokinet 42:499-518. https://doi.org/10.1007/s13318-016-0358-x

21. Pradhan S, Song B, Lee J, Chae JW, Kim KI, Back HM, Han N, Kwon KI, Yun HY (2017) Performance comparison of first-order 
conditional estimation with interaction and Bayesian estimation methods for estimating the population parameters and its distribution from data sets with a low number of subjects. BMC Med Res Methodol 17:154. https://doi.org/10.1186/s12874-017-0427-0

22. Sobiak J, Resztak M, Ostalska-Nowicka D, Zachwieja J, Gąsiorowska K, Piechanowska W, Chrzanowska M (2015) Monitoring of mycophenolate mofetil metabolites in children with nephrotic syndrome and the proposed novel target values of pharmacokinetic parameters. Eur J Pharm Sci 77:189-196. https://doi. org/10.1016/j.ejps.2015.06.017

23. Elbarbry FA, Shoker AS (2007) Liquid chromatographic determination of mycophenolic acid and its metabolites in human kidney transplant plasma: pharmacokinetic application. J Chromatogr B 859:276-281. https://doi.org/10.1016/j.jchromb.2007.09.036

24. van der MAF, Marcus MAE, Touw DJ et al (2011) Optimal sampling strategy development methodology using maximum a posteriori Bayesian estimation. Ther Drug Monit 33:133-146. https://doi.org/10.1097/FTD.0b013e31820f40f8

25. Martial LC, Jacobs BAW, Cornelissen EAM, de Haan AFJ, Koch BCP, Burger DM, Aarnoutse RE, Schreuder MF, Brüggemann RJM (2016) Pharmacokinetics and target attainment of mycophenolate in pediatric renal transplant patients. Pediatr Transplant 20:492-499. https://doi.org/10.1111/petr.12695

26. Tong K, Mao J, Fu H, Shen H, Liu A, Shu Q, du L (2016) The value of monitoring the serum concentration of mycophenolate mofetil in children with steroid-dependent/frequent relapsing nephrotic syndrome. Nephron 132:327-334. https://doi.org/10.1159/000445070

27. Kirpalani A, Rothfels L, Sharma AP, Cuellar CR, Filler G (2019) Nephrotic state substantially enhances apparent mycophenolic acid clearance. Clin Nephrol 91:162-171. https://doi.org/10.5414/ CN109583

28. Filler G, Feber J, Lepage N, Weiler G, Mai I (2002) Universal approach to pharmacokinetic monitoring of immunosuppressive agents in children. Pediatr Transplant 6:411-418. https://doi.org/ 10.1034/j.1399-3046.2002.02039.x

29. Attard TM, Dhawan A, Tredger JM et al (2008) Mycophenolic acid metabolite levels in pediatric liver transplantation: correlation with a limited sampling strategy. J Appl Res 8:135-142

30. Ting LSL, Partovi N, Levy RD, Riggs KW, Ensom MHH (2006) Limited sampling strategy for predicting area under the concentration-time curve of mycophenolic acid in adult lung transplant recipients. Pharmacother J Hum Pharmacol Drug Ther 26: 1232-1240. https://doi.org/10.1592/phco.26.9.1232

31. Baraldo M, Isola M, Feruglio MT, Francesconi A, Franceschi L, Tursi V, Livi U, Furlanut M (2005) Therapeutic mycophenolic acid monitoring by means of limited sampling strategy in orthotopic heart transplant patients. Transplant Proc 37:2240-2243. https:// doi.org/10.1016/j.transproceed.2005.03.090

32. Staatz CE, Tett SE (2007) Clinical pharmacokinetics and pharmacodynamics of mycophenolate in solid organ transplant recipients. Clin Pharmacokinet 46:13-58. https://doi.org/10.2165/00003088200746010-00002

Publisher's note Springer Nature remains neutral with regard to jurisdictional claims in published maps and institutional affiliations. 